\title{
VER, SENTIR, VIVENCIAR E CRER: OS ESTUDOS SOBRE CONSUMO PELOS TRILHOS DA CONSUMER CULTURE THEORY (CCT)
}

\section{SEE, FEEL, EXPERIENCE AND BELIEVE: THE STUDIES ON CONSUMPTION BY RAIL OF CONSUMER CULTURE THEORY (CCT)}

\author{
Adriano de Mendonça Joaquim \\ PPGA-PUC Minas \\ adriano.joaquim@yahoo.com.br \\ Helena da Gama Cerqueira Andrade \\ PPGA-PUC Minas \\ helena_andrade2003@yahoo.com.br \\ Sara Pimenta Resende \\ PPGA-PUC Minas \\ sara@pucminas.br \\ Marcelo de Rezende Pinto \\ PPGA-PUC Minas \\ marcrez@pucminas.br
}

Submissão: 01/10/2018

Aprovação: 26/06/2019

\section{RESUMO}

É notório o aumento do interesse dos pesquisadores de marketing sobre questões envolvendo a Consumer Culture Theory (CCT) no Brasil. Assim, este artigo, de cunho ensaístico, tem por objetivo oferecer à comunidade de marketing um compêndio demonstrando como esta abordagem teórica e metodológica estruturou-se epistemologicamente, como foi construída historicamente e consolidou-se como uma marca e, também, como aqueles que ajudaram a construí-la pensam que seria sua contribuição para que compreendamos os fenômenos do consumo por meio dos seus aspectos culturais e simbólicos. Para isso, estruturou-se em tópicos em que se apresentam a relação entre consumo e a perspectiva interpretativista, discutidos os antecedentes do lançamento da marca CCT e expostas às questões que permearam o lançamento e suas contribuições teóricas e empíricas. Os comentários conclusivos sobre a temática, ao final, motivam os pesquisadores interessados a investir esforços para ampliar esse promissor campo de estudos no Brasil.

Palavras-chave: Consumo, Consumer Culture Theory, Pesquisa em marketing. 


\begin{abstract}
It is notable the increased interest of marketing researchers in issues involving the Consumer Culture Theory (CCT) in Brazil. Thus, this essay article aims to offer the marketing community a compendium demonstrating how this theoretical and methodological approach was structured epistemologically, as it was historically constructed, consolidated as a brand and also as those who helped in their construction they think that this could contribute to that we understand the phenomena of the consumption through its cultural and symbolic aspects. For this, it was structured in topics that show the relationship between consumption and the interpretative perspective, discussing the antecedents of the launching of the CCT brand and exposed the issues that permeated the launch and the theoretical and empirical contributions of the CCT. The concluding comments on the subject, in the end, motivate interested researchers to invest their efforts to expand this promising field of studies in Brazil.
\end{abstract}

Key words: Consumption, Consumer Culture Theory, Marketing Research.

\title{
INTRODUÇÃO
}

Há mais de uma década, a CCT (acrônimo de Consumer Culture Theory) passou a fazer parte do universo das publicações acadêmicas na área de marketing no Brasil. No decorrer desse período, mesmo enfrentando opiniões controversas, se consolida entre as abordagens de investigação mais utilizadas pelos responsáveis por estudos indutivos na área de marketing no Brasil.

Provas disso estão nos resultados apresentados, nos últimos anos, pelos coordenadores da área de Marketing do EnAnpad, os quais registram que o tema que recebe trabalhos sobre cultura e consumo, criado em 2009, tem sido o segundo mais demandado dentre os dez que englobam a área de marketing. Além disso, deve-se mencionar que o tema intitulado "Consumo, Sociedade e Materialismo", criado em 2017 nos Seminários em Administração (SemeAd) é o que tem recebido o maior número de submissões para o evento. Vale ressaltar, ainda, o Congresso Latino-Americano de Varejo - CLAV da FGV/SP que, também, tem uma trilha acadêmica específica para receber trabalhos sobre Cultura e Consumo.

Em termos de divulgação acadêmica, isso significa que tanto os dois maiores encontros acadêmicos da área de Administração do Brasil quanto os dois maiores encontros de marketing do país destinam atenção específica para esta abordagem teórica e metodológica de se estudar o consumo.

É bem verdade que já se deu vasta publicidade, nesses encontros, aos estudos bibliométricos e às possibilidades de pesquisas ao se usar a CCT. Todavia, persiste em nosso entender a necessidade de uma publicação que preencha o vazio sobre como um aluno iniciante da pós-graduação em Administração ou um pesquisador da área de marketing pode compreender como esta abordagem teorética e metodológica estruturou-se epistemologicamente, como foi sua construção histórica, a consolidação como uma marca e, também, como aqueles que ajudaram em sua construção pensam como esta poderia contribuir para que compreendam-se os fenômenos do consumo por meio dos seus aspectos culturais e simbólicos.

É neste solo que este trabalho se assenta. Fruto não só de pesquisas bibliográficas mas, principalmente, das discussões travadas semanalmente por um grupo de alunos de pósgraduação em Administração que buscou, a partir da demanda do orientador, desvelar os meandros da CCT e estruturá-la para que aqueles que ingressassem no programa conseguissem rapidamente entendê-la e pudessem adotá-la. Dito de outra forma, o objetivo 
desse artigo é trazer para o debate uma discussão acerca das principais questões envolvendo os estudos sobre consumo à luz da Consumer Culture Theory (CCT) compreendendo suas articulações com a perspectiva interpretativista de pesquisa, um pouco da sua gênese, bem como suas contribuições para a área de marketing.

Mister ressaltar que o texto não foi construído com o intuito de ser um "manual para dummy" sobre CCT. Pelo contrário, coloca-se como a ponta do fio do novelo para os que desejam iniciar seus estudos e, assim como nós, não tinham ou não sabiam como começar.

Neste diapasão, optamos por dividi-lo expondo as fases pelas quais tivemos de passar para que conseguíssemos construir o nosso entendimento sobre a trajetória da CCT para, por fim, apresentarmos a relação de publicações internacionais e nacionais que nos orientaram e que, por meio deste artigo, desejamos compartilhar com os que queiram estudá-la.

\section{O CONSUMO E A PERSPECTIVA INTERPRETATIVISTA DE INVESTIGAÇÃO}

De antemão, precisamos nos situar no tocante ao momento em que a perspectiva interpretativista chega ao campo do consumo na área de marketing. Conforme salientado por Kassarjian and Goldstein (2010), a emergência da escola de comportamento do consumidor se dá por volta dos anos 1940 e sua base teórica encontra respaldo nas análises psicológicas do comportamento econômico. Nessa época, o interesse estava na proposição de modelos de comportamento de compra baseados no processo de decisão. Essa perspectiva se consolidou e tornou-se dominante no campo do marketing nas décadas seguintes até chegar aos dias atuais.

No entanto, principalmente a partir dos anos 1980, ganha destaque a emergência da cultura do consumo que passa a jogar luz sobre não somente as questões individuais, mas essencialmente nas relações sociais e na influência da cultura nas ações de consumo. Nesse sentido, a perspectiva interpretativista passa a assumir um lugar de destaque, porém, sem se sobrepor à abordagem positivista da Consumer Behavior.

Dessa forma, é interessante enfatizar que investigar fenômenos ligados ao consumo utilizando a abordagem interpretativista é como se embarcássemos em uma viagem e, ao decidir fazê-la utilizando os trilhos oferecidos pela ótica da cultura, tem-se a sensação de que se comprou uma passagem apenas de ida, pois os caminhos por onde passa esse "trem" estão inexoravelmente atrelados ao apreciar paisagens e a experimentar sensações, digamos, não corriqueiras para quem pesquisa consumo. Nos permitimos abordá-lo desta forma, pois estamos, neste momento, chamando a atenção para o conceito amplo, paradoxal e, por vezes, antagônico que as interpretações sobre o tema podem oferecer.

Etimologicamente, a palavra consumo deriva do latim consumere, que significa "usar tudo, esgotar e destruir". Contudo, se buscarmos sua etimologia a partir da língua inglesa, consummation, pode ser traduzida como "somar e adicionar". Tem-se, portanto, que aqueles que desejam estudá-lo, deveriam vê-lo enquanto um processo social tanto elusivo quanto ambíguo. Elusivo porque só se toma consciência de sua existência quando é classificado como "supérfluo", "ostentativo" ou, até mesmo, "conspícuo". Ambíguo porque, muitas vezes, é visto como "uso e manipulação" e/ou como "experiência"; em outras, como "compra" e, ainda, como "exaustão, esgotamento e realização" (Barbosa \& Campbell, 2006). Decerto, essas contradições etimológicas contribuíram para que, por décadas, os estudos sobre Consumo fossem abordados ou por sua conotação negativa ou "renegado" pelos estudiosos que minimizaram sua importância no contexto social.

Duarte (2010), ao tentar entender o motivo pela qual o consumo demorou para se tornar uma área de estudo consolidada na antropologia, aponta pelo menos dois motivos para tal situação. Um deles tem a ver com as percepções acadêmicas nas quais a produção ganha centralidade e importância, relegando-lhe um papel secundário e ideologicamente 
constrangido. Um segundo motivo estaria relacionado à forte influência do modelo marxista, cujos efeitos se desdobram sobre a produção e sobre o trabalho.

Nesse contexto, não se pode negar a influência da Escola de Frankfurt que, certamente, contribuiu para posicionar o consumo como um "vilão". Pesquisadores que adotavam esta corrente para estudá-lo, o viam como responsável pela expansão da produção de massa que, por sua vez, promovia a comoditização da cultura e, neste contexto, colocavam os consumidores como passíveis de terem seu comportamento conduzido por ações publicitárias (Graeber, 2011).

Isso começa a mudar em meados da década de 1980, quando o tema passou a ser objeto de estudos Antropológicos, Sociológicos, Históricos e Culturais, que começaram a investigar o comportamento de consumidores dentro de um contexto de subculturas e constataram que as pessoas, em vez de serem vítimas passivas de manipulação, na verdade, eram agentes ativos, criativos e críticos em sua transformação e apropriação dos bens materiais (Graeber, 2011). Este fato abriu novas possibilidades para estudar v a temática como algo que emergiria da cultura. Nesta linha, surgem autores como Wilk (2004), Barbosa e Campbell (2006) e Graeber (2011) que, por meio de suas pesquisas, demonstraram que os estudos sobre Consumo incorporam, consciente ou inconscientemente, uma carga de valores morais. Wilk (2004) ressaltou que os estudos sobre consumo tinham tanta plasticidade que impossibilitariam defini-lo. Para ele, o tema é desses conceitos sobre o qual todos falam, mas não discutem a fim de chegarem em uma definição comum. Exemplo disso pode ser visto quando se estudam as relações entre consumo e moralidade que parecem, segundo ele, contribuir para o caráter elusivo do tema; mais do que isso, o autor afirma que questões morais estão imbricadas no significado de consumo em um nível fundamental.

Neste fito, Wilk (2004), a partir da linguística cognitiva, desenvolve uma metodologia para tentar compreender essa relação e, ao analisar expressões metafóricas utilizadas na Língua Inglesa, consegue concluir que tais sentenças contribuíam para associar o consumo a determinados conceitos, como, por exemplo: de senilidade, perda de energia, valor em declínio, desaparecimento, morte e, até ao ato de comer.

Ao nos debruçarmos sobre o parapeito da janela do trem que nos leva pelas estradas dos estudos sobre consumo, vemos paisagens com diversas matizes de cores e relevos que nos dão a noção dos espaços geográficos. Alguns destes foram construídos por estudiosos como Douglas e Isherwood (1979), Appadurai (1986), Friedman (1994) e Miller (1987, 1995, 1997, 1998, 2001), os quais, à sua maneira, desenvolveram teorias sobre consumo que, hoje, ao serem estudadas em conjunto, propiciam vê-las como uma "narrativa comum" para abordar o tema (Graeber, 2011).

A "história" narrada por esses autores demonstra ser por meio das compras que as pessoas encontram prazer e satisfazem desejos, sendo estes normalmente associados à supressão de alguma "falta", em um continuum no qual o final do ato consumista é o próprio desejo de consumo (Retondar, 2007).

O consumo passa, então, a ser reconhecido como um elemento que mediaria relações e processos estabelecidos na sociedade moderna e constata-se, também, que ao consumir um determinado produto, as pessoas criavam seus próprios significados e que estes, por sua vez, possuiriam uma natureza simbólica (Graeber, 2011; Retondar, 2007). Em suma: seria por meio dos carros que dirigimos, das roupas que vestimos, das músicas que escutamos e dos alimentos que ingerimos que construiríamos, desconstruiríamos e reconstruiríamos nossas identidades (Hall, 2011).

Isso nos faz perceber como Retondar (2007) foi assertivo ao constatar:

que a esfera contemporânea do consumo seria um sistema de comunicação social, aonde os diversos produtos e bens são constantemente associados a distintos universos 
significativos e, ainda, que tal associação se daria de maneira cada vez mais flexível e que, o ato de consumo transformar-se-ia, neste caso, num ato de adesão simbólica em que a escolha do objeto se torna uma escolha estratégica, por meio da qual o consumidor vai continuamente definindo e redefinindo sua identidade (Retondar, 2007, p.145).

Percebemos que, talvez, tenha sido nesse movimento que o consumo constituiu-se como um campo autônomo, sendo cada vez mais abordado pelos pesquisadores da Antropologia, os quais passam a ganhar importância e serem procurados por gestores de Marcas, não apenas para a realização de pesquisas sobre a temática (que até então eram conduzidas, em sua maioria, por profissionais da Psicologia), mas, também, para dirigirem seus departamentos de marketing; e os journals, a exemplo do Journal of Consumer Behaviour, passaram a abordar a importância de se compreender o contexto social nos estudos do comportamento do consumidor (Graeber, 2011; Retondar, 2007).

Assiste-se, então, à maturação das pesquisas de consumo pelo campo das Ciências Sociais, em especial na sua correlação com a cultura, uma vez que Holbrook (1987) define "pesquisa de consumo" como o "estudo da aquisição, uso e descarte de produtos tendo o consumo em si como foco" priorizando a compreensão desse processo, incluindo possíveis intercorrências no caminho - diferentemente das pesquisas de marketing, que, na visão deste autor, teriam o entendimento do comportamento do consumidor como principal objetivo. Holbrook (1987) defendia que o termo consumer research deveria se referir ao estudo do consumo em todos os seus aspectos e não apenas em relação ao comportamento do consumidor.

A partir desse contexto de aparente falta de coesão é que Campbell (2004) propõe uma forma de se classificar em quatro categorias os diversos olhares sobre o consumo no que ele vai denominar "imagens do consumidor". A primeira delas, central na teoria econômica, é o consumidor como um ator ativo, que calcula e raciocina, alguém que aloca recursos para maximizar a vantagem obtida. A segunda categoria representa o consumidor passivo, manipulado e explorado, típico dos textos críticos oriundos dos autores da Escola de Frankfurt. Já a terceira categoria se destina a representar aquele consumidor manipulador dos significados simbólicos vinculados aos produtos. Por fim, a quarta categoria sugere o que ele vai denominar de "consumidor artesão", ou seja, aquele indivíduo que consome principalmente por um desejo de tomar parte em atos criativos de expressão de sua individualidade.

Para Thompson (1991, p. 63), a pesquisa do consumo, para dar conta de toda essa complexidade de interpretações, escolas e influências, sofreu um "alargamento de suas orientações filosóficas e metodológicas". Neste contexto, para atender com mais assertividade aos objetivos desses estudos, começa a tomar corpo a pesquisa interpretativista, em oposição a uma epistemologia positivista preponderante até meados da década de 1980, a qual procurava explicar e prever o que acontecia no mundo social por meio de regularidades e relações causais entre os elementos constituintes dos objetos analisados (Burrel \& Morgan, 1979; Pinto \& Santos, 2008).

O interpretativismo, como o próprio nome sugere, tem como principal entrega a interpretação do fenômeno estudado. A fim de obter uma interpretação verídica, o pesquisador lança mão de estratégias: empatia e intuição. A empatia é necessária uma vez que o pesquisador deve ser capaz de aprender sobre a realidade dos outros e entender o que ele pensa, sente e acredita; já a intuição é fundamental para ajudá-lo a interpretar o fenômeno estudado e transformá-lo em conhecimento. Para tal, uma metodologia muito utilizada pelos pesquisadores é a observação participante (Hirshman, 1986). Thompson (1991), já no início 
da década de 1990, aponta alguns estudos interpretativistas, tais como os de Belk, Sherry and Wallendorf (1988), McCracken (1986) e Hirschman (1986).

É neste terreno que lançaram-se as sementes que deram origem ao texto seminal no qual Arnould and Thompson, em 2005, cunhariam o termo Consumer Culture Theory (CCT), fundado na constatação, mesmo que ainda não consensual, da importância de se compreender o consumo, e não apenas o comportamento do consumidor, levando em consideração os contextos sociais e os aspectos simbólicos produzidos culturalmente que o cercam; além da necessidade de se investigar esse fenômeno por meio de uma metodologia que aproximasse o pesquisador do campo pesquisado, possibilitando a captação dos aspectos subjetivos que dão a um determinado objeto de pesquisa o caráter único que ele possui.

No tópico a seguir, apresentaremos como iniciou, literalmente, a jornada para a criação desta escola de pensamento e, no decorrer da discussão, o principal conjunto de artífices e fundadores dessa história.

\section{BEFORE CCT BRAND - ENTENDENDO A HISTÓRIA}

Pode-se afirmar que a história da CCT inicia a partir de uma inquietação percebida entre alguns pesquisadores do campo do comportamento do consumidor. Em 1985, Russell Belk, então jovem pesquisador e professor universitário da Universidade de Utah, envia uma carta a outros nove pesquisadores (Elizabeth Hirschman, Harold Kassarjian, Sidney Levy, Olson, Dennis Rook, John F. Sherry, Melanie Wallendorf e Victoria Wells), os convidando a passarem o verão do ano seguinte (de 13 de junho a 25 de agosto de 1986) percorrendo os EUA, em um motor home, de ponta a ponta (a viagem começou em Los Angeles e se encerrou em Boston), observando e entrevistando americanos em diferentes contextos, a fim de conhecer e registrar suas histórias e relações com o consumo.

Os dados e registros foram feitos em lugares diferentes dos utilizados usualmente à época nos estudos sobre comportamento do consumidor, quais sejam: supermercados e shoppings centers. Ao invés disso, eles foram ao encontro de consumidores que estavam nas mais diferentes situações e locais de consumo, como por exemplo:

(...) lojas de departamento, concessionárias de automóveis novos e usados, garage sales, mercados de pulgas, leilões, lojas do Exército de Salvação, atrações turísticas, inspeções imobiliárias, motéis, lojas de fast food e Restaurantes de 4 estrelas, churrascos de quintal, piqueniques, casamentos, bordéis, clubes de campo, bares, salões de dança, lojas de animais, Metropolitan Opera, concertos de rock, etc. (Belk, 1991, p.1).

Percebe-se que a intenção primaz da viagem arquitetada por Belk, além de observar e registrar o comportamento dos consumidores em formatos, lugares e perspectivas diferentes daqueles que os pesquisadores do consumo haviam estado ou feito, foi viabilizar mais uma forma de se pesquisar o comportamento do consumo e, de alguma forma, irromper com os paradigmas ontológicos e epistemológicos que dominavam as pesquisas daquela época e, por consequência, testar novos métodos de coleta de dados que não fossem os tradicionais questionários "fechados", as escalas e os experimentos.

Ideia "descabida"? Não para aqueles que não só aceitaram o convite, como também trouxeram outros pesquisadores, formando um grupo de 25 pessoas. Nascia a Consumer Behavior Odyssey, projeto este, precursor da CCT (Belk, 1987; 2014; 2017).

Com o apoio financeiro do Marketing Science Institute, de agências de publicidade e das universidades dos participantes, a metodologia do trabalho contou com entrevistas em 
profundidade e observações participantes, as quais foram registradas por meio de fotografias, filmagens e diários de campo.

O trabalho rendeu, além de artigos científicos, um livro, um vídeo e várias apresentações em conferências. Todavia, o resultado mais significativo foi, sem dúvida, o fato de que a Odisseia possibilitou com que os pesquisadores participantes se lançassem no campo da pesquisa qualitativa de consumo (ainda que sob críticas e questionamentos de muitos), que mais à frente se denominaria Consumer Culture Theory (Belk, 2017).

Você pode estar se perguntando. De onde surgiu tamanha inquietação? Belk (2014) explica que, a partir do final da década de 1950, criou-se uma "crença" de que somente a pesquisa quantitativa fornecia dados "sérios" aos pesquisadores. Essa "crença", respaldada pelas escolas de Administração norte-americanas e seus journals, foi alimentada pela crescente utilização dos computadores e de softwares estatísticos de análise, novidades na época. Paralelamente, a psicologia cognitiva experimental também ganhava campo na investigação do comportamento do consumidor e, em pouco tempo, sua metodologia tornouse símbolo de rigor científico e as associações como a American Marketing Association (AMA) e a Association for Consumer Research (ACR), além de publicações como o Journal of Consumer Research (JCR), também respaldavam a utilização de métodos quantitativos em pesquisas (Belk, 2014).

Kassarjian (1987), assim como Sherry (1987), participantes da Odisseia, afirmam que muitos dos pesquisadores convidados por Belk estavam se sentindo "entediados" com os caminhos que a pesquisa de consumo estava tomando e vislumbraram naquele projeto uma oportunidade para o surgimento de novos rumos. Vale lembrar que fazem parte da construção dessa história os manifestos que "convocavam" pesquisadores do consumo a se unirem na mesma direção como, por exemplo, o "Manifesto for a Consumer Behavior of Consumer Behavior" (Belk, 1984).

Belk (2014) sinaliza que alguns autores já haviam estudado o consumo de forma qualitativa antes da Odisseia, tais como Veblen (economia), James (Psicologia), Simmel e Durkheim (sociologia); Malinowski, Geertz, Sahlins, Mead, Bateson, Douglas, Miller, Appadurai, Kopytoff, Rouch e Flaherty (antropologia); além de Campbell, Csikszentmihalyi e Eugene Rochberg-Halton (interdisciplinares) e que, para estudarmos o consumo via CCT, fazse necessário compreender o pensamento desses autores.

Não haveria como deixarmos de fora desse rol de pensadores, o trabalho de Nicosia e Witkowski (1975) intitulado "The Need for a Sociology of Consumption" que, apesar de se valer de dados quantitativos, põe luz na discussão sobre valores e normas culturais e consumo, bem como uma série de conferências realizadas entre 1980 e 1984, no âmbito da American Marketing Association - AMA, em que se discutiram a utilização de pesquisa qualitativa nos estudos de consumo e fomentaram movimentos favoráveis a essa "quebra de paradigma", tal como foi a Consumer Behavior Odyssey.

Da leitura dos artigos escritos pelos participantes da "jornada" sobre como viveram e viam a Odisseia em si, percebe-se que eles se auto submeteram a uma forma de trabalho e de aprendizado fora do convencional. Por diversas vezes, esses autores citam Jaguer (1975), que afirmava que as jornadas eram tradicionais na busca pelo conhecimento na Grécia Antiga e explica que é comum o uso de metáforas similares a esta quando se refere a uma busca por conhecimento científico: "descoberta", "progresso" e "avanço". Em suas palavras, "A jornada é separada do comum e está fora da vida diária; é nesse sentido sagrado. O teórico se afasta do familiar e procura "o que é emergente, imprevisível, encantador e inspirador" (Jager, 1975, p.239, como citado por Belk, 1987a).

Apropriando-se sabiamente dessa ideia, Belk (1987a) acrescenta outras características ao conceito de "jornadas" que contribuem para a busca de conhecimento, quais sejam: a austeridade dessas viagens - os confortos são deixados para trás não apenas para tornar a 
viagem viável, mas também para tirar os pesquisadores da sua "zona de conforto" e ajuda-los a questionarem e vivenciarem outras realidades; o participante ideal é aquele "autossuficiente" - está independente e perseverante; os viajantes têm seus olhares direcionados para a tarefa em questão, e não para seus companheiros ou suas ferramentas (que são o meio, mas não o fim da viagem); o viajante aceita o tempo linear da jornada (com seu caminho estreito, ocorrências singulares, eventos únicos e irrepetíveis e pessoas e lugares estranhos que talvez nunca mais veja novamente); e por fim, o autor afirma que em movimentos como este "a jornada começa e termina com a comunidade. A partida é necessária para aprender, e o retorno é necessário para ensinar" (Belk, 1987a, p.357).

Tudo isso foi vivenciado pelos participantes da Odisseia, que é repetidamente descrita como uma "experiência de aprendizado", e na qual o "mudar de ambiente" foi um ingrediente essencial para precipitar novas formas de conhecimento. E, certamente, ter tido a oportunidade de observar o mundo como realmente era e, a partir disso, propor novas formas de conhecimento é descrito nos depoimentos publicados por eles como um privilégio.

Em nossa opinião, vale destacar especialmente os de Kassarjian (1987), que viu na Odisseia uma oportunidade de se criar algo novo, inédito: dados descritivos que testam, provam e geram teorias, além de ajudar a compreender melhor o fenômeno do comportamento de consumo. Também seria uma forma de aproximar pesquisadores "demasiadamente teóricos" da pesquisa empírica e de se aproximar de campos antes nunca estudados, como mercados das pulgas, circos e feiras.

Para Wallendorf (1987), co-organizadora da "aventura" liderada por Belk, a principal pergunta sobre a jornada foi: "qual a grande diferença desse projeto"? A resposta que ela encontrou não recaía sobre a natureza qualitativa das investigações, e sim sobre o fato de que "nós estamos sempre na estrada", ou seja, os participantes estavam sempre em movimento. Afinal, a metodologia qualitativa e suas ferramentas podiam não ser bem aceitas entre as escolas e departamentos de marketing, porém já eram tradicionais entre as pesquisas das Ciências Sociais, portanto, não seria uma inovação trazida da Odisseia; mas pesquisa em movimento sim, essa seria uma inovação.

Com essa reflexão, a autora, acreditamos, quis dizer que, ao invés de eleger, como de costume, um tema e um campo de pesquisa específico e, a partir dele, realizar um estudo aprofundado como é feito por uma metodologia etnográfica "tradicional", a Odisseia definiu um escopo de pesquisa muito amplo, qual seja: o consumo do americano e, com isso, incluiu toda a gama de atividades de aquisição, uso e disposição dos consumidores.

Wallendorf (1987) retrata, em seu depoimento sobre a Odisseia, fatos curiosos como por exemplo, de que, assim como eles, havia muitos outros viajantes. Americanos que também estavam em movimento pelo país e cuja viagem era, obviamente, uma forma de consumo em si mesmo.

Tanto para os pesquisadores, quanto para os viajantes com quem eles cruzavam, havia uma certeza: de que há muitas incertezas sobre o que estava por vir na estrada. A seguir, tentaremos sintetizar como foi esse "porvir" construído por esses artífices da CCT.

\section{THE BIRTH OF CCT BRAND - CONSTRUINDO A HISTÓRIA}

Os anos que se seguiram após o Consumer Behavior Odyssey foram marcados por pesquisas que exploraram o consumo em seus aspectos sociocultural, experiencial, simbólico e ideológico (Arnould \& Thompson, 2005). Porém, até 2005, o movimento liderado por Belk com a Odisseia não tinha uma denominação, até que Arnould e Thompson, a convite da ACR, publicaram um artigo, hoje seminal para quem estuda CCT, no qual propuseram o nome Consumer Culture Theory e referiam-se a ela como uma 
(...) família de perspectivas teóricas que aborda as relações dinâmicas entre as ações do consumidor, o mercado e os significados culturais" que exploram a "distribuição heterogênea dos significados e a multiplicidade de grupos e manifestações culturais que existem nas diversas formações sócio históricas atuais" (Arnould \& Thompson, 2005, pp. 868-869).

E por que incluir "cultura de consumo" no nome? A explicação dos autores sobre o termo conceitua um sistema interconectado de imagens, textos e objetos que determinados grupos de consumidores utilizam para construir significados, além de identificar e orientar as experiências de seus membros. Hoje é possível afirmar que a CCT é uma "marca" "consumida" por um grupo de pesquisadores que, apesar de muitas vezes possuírem diferentes abordagens e objetivos de pesquisa, compartilham uma característica em comum: a orientação teórica para o estudo da complexidade cultural.

Aqui está, em nossa opinião, a importância de se formatar e dar um nome para o "movimento": gerar identificação e respaldo entre os pesquisadores e, consequentemente, fortalecer o campo de pesquisa. Afinal, não foram (e continuam sendo) poucas as críticas que o grupo recebeu ao longo dos anos, tanto à epistemologia interpretativista quanto às metodologias utilizadas, a aplicabilidade e validade científica dos resultados dos estudos (Belk 2014; 2017).

A crescente influência da CCT nos estudos de consumo, além do fato dela contar com a presença de pesquisadores de todas as áreas ao redor do mundo, levaram Maccinnis e Folkes (2010) a posicioná-la como uma das três perspectivas teórico metodológicas para se estudar o comportamento do consumidor e Gaião, Souza e Leão (2012), por sua vez, classificarem-na como uma nova escola de pensamento de marketing. Tal constatação levou em consideração o fato de que a CCT atendia aos critérios para ser classificada como tal, pois representa um corpo substancial de reconhecimento acadêmico; é desenvolvida por vários estudiosos e busca descrever ou explicar pelo menos um aspecto sobre o que, como, quem, por que, quando e onde se dão as atividades de marketing. No entanto, não se pode deixar de mencionar que a abordagem não se sobrepôs às tradicionais, mas sim, veio a oferecer uma perspectiva alternativa ao mainstream do campo.

Ao se discutir sobre a abrangência dos estudos em CCT, não se pode olvidar outra seminal contribuição de Arnould e Thompson, publicada em 2007, na qual revisam o artigo de 2005 e delineiam um "framework teorético" que, além de determinar os focos para os estudos da CCT, nos auxiliou, enquanto pesquisadores, a definir e, consequentemente, guiar nossos estudos sob a perspectiva desta escola de pensamento.

Este framework é composto por quatro estruturas de interesse teórico comum divididas em quatro grandes áreas de investigação. 
Figura 1 - Framework CCT
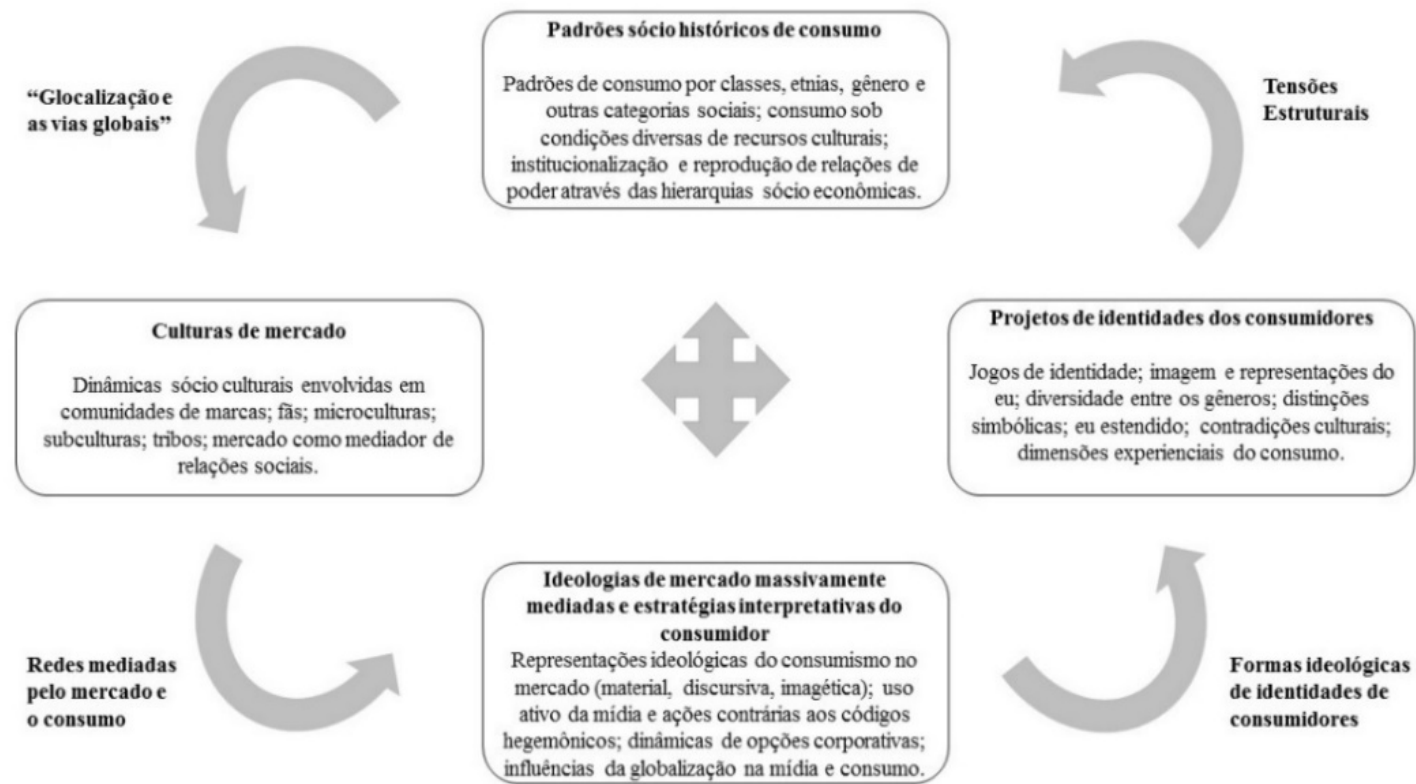

Fonte: Arnould e Thompson, 2007

Contudo, no decorrer das nossas discussões "intragrupo" com o fito de interpretar esse framework percebemos que, longe de serem independentes, as quatro estruturas são interligadas, apesar de que uma ou duas delas provavelmente se sobreponham em um ou outro estudo. Neste sentido, constatamos que seria importante nos debruçarmos mais atentamente sobre os temas e interseções pertencentes a cada uma dessas estruturas que compõem a Figura 1 para que conseguíssemos identificar mais assertivamente em qual das estruturas os pesquisadores que publicavam sob a égide da "marca" CCT concentravam seus esforços e, com isso, pudéssemos mais facilmente não só definir quais autores e trabalhos comporiam o framework teórico para cada uma de nossas publicações, como, também, identificássemos eventuais gaps de pesquisa.

Assim, para nos mantermos coerentes ao propósito inicial deste trabalho, natural oferecermos, na sequência, uma síntese do nosso entendimento sobre o que versa cada uma das interseções. Dessa forma, um iniciante nos estudos em CCT, acreditamos, conseguiria ter uma ideia de como ela se coloca em termos de áreas de pesquisa, que são:

As formas ideológicas de identidade de consumidores referem-se aos estudos que investigam a cultura de consumo no que diz respeito à relação entre os consumidores e suas escolhas simbólicas a fim de forjarem suas identidades. Essa esfera de estudo rompe com a visão pré-concebida de "consumidores passivos da indústria e propaganda capitalista" e passa a examinar uma dinâmica mais complexa, na qual os consumidores exercem agência sobre aquilo que consomem e influência sobre os quadros culturais colocados pelas ditas "ideologias dominantes". Trata-se de um quadrante muito explorado pelos pesquisadores da CCT, principalmente em estudos empíricos sobre consumo.

Já os trabalhos que exploram as tensões estruturais versam sobre as relações entre "reprodução social", genética e "transformação da identidade"; ou seja, seus pesquisadores buscam responder à seguinte pergunta: os indivíduos podem, por meio da cultura de consumo, transcender as orientações internalizadas ou habituadas em seus seres - orientações que 
emanam da sua socialização, no que diz respeito à classe, gênero, etnia e outras dimensões da estrutura social? Importante ressaltar que nessa esfera de investigação, os autores que usam a CCT procuram avançar para além da oposição dicotômica que normalmente é colocada entre o determinismo sociológico e autonomia / autenticidade existencial.

As pesquisas que utilizam a quadrante globalização e as vias globais, via de regra, investigam a influência e a relações entre "estruturas globalizadoras", ligadas às instituições de economia global (como a difusão global da mídia de entretenimento e as ações de marketing de corporações transnacionais) e culturas e economias locais, bem como as homogeneidades, heterogeneidades e tensões que essas "fusões" podem gerar.

Por fim, redes mediadas pelo mercado e consumo buscam, a partir da compreensão de que a cultura é uma rede dinâmica que promove interações e que as ações, emoções e reações dos atores sociais são moldadas por influências institucionais locais, analisar as formas como essas redes mediam relações sociais, identidades performativas, práticas sociais e experiências do consumidor.

Percorridas as interseções das áreas de pesquisa propostas por Arnould e Thompson (2007), faz-se necessário alertar àqueles que desejam enveredar-se por seus meandros que, por suas características ontológicas e pelos métodos de investigação adotados por seus pesquisadores que, diferentemente da Behaviorial Decision Theory - BDT e a Information processing, a CCT busca na heterogeneidade, na multiplicidade de significados e na coexistência dos diferentes arranjos socioeconômicos e culturais de uma determinada sociedade compreender práticas de consumo, levando-se em consideração a "vida vivida" daqueles que estejam sendo objeto de investigação. Por isso, dois importantes autores a serem referenciados para quem estuda CCT é Geertz (1973), que propôs o estudo da cultura por meio das teias de significados; e Kozinets (2010), que chama a atenção para a plasticidade e a dinâmica das relações culturais inter e intragrupos sociais.

Essa discussão nos leva por luz num outro ponto importante dentro dos estudos da CCT, qual seja: a falácia sobre a centralidade dos seus estudos recaírem na agência e nos indivíduos. É verdade que eles são majoritários entre os trabalhos americanos, mas, ao voltarmos nossas atenções para o outro lado do Atlântico, e isso levou algum tempo, percebemos que havia estudos que colocavam no centro da discussão as dinâmicas dos mercados com o objetivo de compreender como eles se formam, transformam e legitimam-se.

Com isso, queremos alertar que não é pressuposto dos estudos da CCT estudar, por exemplo, exclusivamente a construção de identidade por meio do consumo. Pode-se e devese, também, tentar explicar fenômenos que ocorram em determinados contextos, como fizeram Sandikci e Ger (2010) quando estudaram o uso do véu por jovens turcas.

Por fim, gostaríamos de fazer uma última ponderação antes de passarmos para o próximo tópico da nossa viagem: a importância de se perceber que a CCT, diferentemente do que se imagina, não é ateórica.

No decorrer das nossas leituras e discussões percebemos que ela se desenvolve a partir dos enlaces teóricos que seus pesquisadores fazem com autores oriundos, principalmente, da antropologia, da sociologia ou mesmo interdisciplinares já citados. Com isso, na nossa percepção, de um lado contribuem para testar a validade dessas teorias no mundo do consumo e, de outro, trazem para literatura do marketing autores que, via de regra, até então tinham pouca inserção na literatura da área tais como Theodor Adorno, Michel Foucault, Pierre Bourdieu, Clifford Geertz, Mary Douglas, Michel de Certeau, Igor Kopytoff, Alan Warde, Daniel Miller, dentre outros, e hoje lutam para construir teorias próprias como as que Belk desenvolveu como fruto dos estudos feitos no âmbito da CCT - tais como Extended Self, Sharing, Gift-giving.

Na próxima seção apresentaremos uma relação de autores representativos, fruto não apenas das pesquisas bibliográficas feitas durante esse último ano pelo grupo de estudos, mas, 
principalmente, das discussões intragrupo sobre aquilo que acreditamos ser a literatura de base para os que desejam conhecer a CCT em seus aspectos ontológicos, epistemológicos, metodológicos e teoréticos, tanto em nível internacional quanto nacional.

\section{AFTER CCT BRAND - CONTRIBUIÇÕES TEÓRICAS E EMPÍRICAS}

Desde o início, a intenção dos autores ao elaborar esta discussão não foi simplesmente dar créditos aos pesquisadores que participam da construção da CCT, mas, sim, municiar os alunos de pós-graduação em Administração e pesquisadores da área de marketing que, assim como nós, tenham se deparado fortuitamente com esta sigla no decorrer das suas leituras, com as referências necessárias para que tenham por onde começar a conhecê-la.

Cabem, antes de apresentá-la, algumas afirmações: primeiro, além das referências utilizadas neste artigo, encontra-se a literatura produzida e citada tanto por pesquisadores internacionais quanto nacionais; segundo, quase a totalidade dos artigos listados encontra-se disponível para download no portal de periódicos da Capes, através do Sistema Café e, por fim, esta está longe de ser uma lista fechada e exaustiva: trata-se, como dito no início deste artigo, da "ponta do fio do novelo" e, portanto, não só pode como deve, sistematicamente, receber contribuições de todos.

Por fim e não menos importante, esperamos que por meio dela possibilitemos ao leitor a capacidade de organizar suas leituras, estudá-las, compreendê-las, explorá-las e se tornar, assim como nós, partícipes da comunidade da CCT no Brasil. Não temos a intenção aqui de ser exaustivos nessa lista, até mesmo porque são muitas as trilhas já consolidadas no campo. A proposta é oferecer ao leitor um apanhado geral com vistas a apontar autores, publicações e temáticas que consideramos interessantes.

Inicialmente, evidenciaremos artigos e autores já citados neste trabalho e, portanto, não poderíamos deixar de começar por Belk (1987a, 1991, 2009, 2014, 2017) que, além de idealizador da Odisseia, publicou e publica até hoje importantes trabalhos na área. Trabalhos que, além de empíricos, agregaram em teoria e conhecimento. Além de Sharing (2009), que municiou as discussões sobre consumo colaborativo e economia de compartilhamento, contribuindo para a construção dos conceitos de rituais de consumo (1987b), posse (1992), self estendido (1988; 2013) e relações consumidor-marca (Belk \& Tumbat 2005).

Da Odisseia derivaram muitos trabalhos. Dentre eles destacamos "O sagrado e o profano no comportamento do consumidor" (Belk, Wallendorf \& Sherry, 1989) que, além de fazer uma contribuição teórica, discute a relação entre consumo e moralidade pontuada no início deste trabalho. Por fim, dentre muitas outras contribuições do autor, destacamos um artigo realizado em parceria com a professora e pesquisadora brasileira Letícia Casotti, no qual analisam a história e o cenário da pesquisa etnográfica em cultura e consumo no Brasil e no mundo (Belk \& Casotti, 2014).

Outro importante autor é Sherry (1983) que desenvolveu, antes mesmo da Odisseia, um estudo antropológico sobre a prática de gift giving, a fim de compreender com mais subjetividade a prática de trocas de presentes. Em seu turno, Hirschman (1986) elaborou um estudo comparativo entre a filosofia e o método humanista e a filosofia e o método positivista no contexto das pesquisas de marketing. Com isso, ela ressaltou as diferenças entre ambas as epistemologias e evidenciou as peculiaridades e aplicações da pesquisa interpretativa. Seus textos contribuíram para incluir esta epistemologia no rol das pesquisas de consumo, em contraposição ao establishment da época.

Arnould and Thompson (2005; 2007), além de designarem o nome deste campo de estudo, construíram o framework que hoje é referência sobre a atuação teorética da CCT e desenvolveram trabalhos fundamentais para quem estuda consumo nessa perspectiva. Thompson, Arnould and Giesler (2013) elaboraram uma crítica aos estudos da área, que 
muitas vezes privilegiam um modo de análise "hiperindividualizado", priorizando a agência do consumidor em detrimento das forças sociológicas e mercadológicas, dentre outras variáveis estruturais, que atuam sobre ele. O artigo fomentou discussões recorrentes na CCT sobre os limites da pesquisa de consumo no atendimento às finalidades gerenciais e, também, sobre sua validade quando estiver centrada no consumidor, desconsiderando ou "pouco considerando" seu contexto macrossocial.

Em 2011, Askergaard and Linnet defendiam que "já era hora” de os estudos da CCT expandirem a contextualização das experiências do consumidor, ou seja, a "vida vivida" com outra contextualização, que se refere às influências sistêmicas e estruturantes de sistemas de mercado e sociais, que não necessariamente são sentidos ou experimentados pelos consumidores em suas vidas diárias e, portanto, não são expressas por eles. Ou seja, é preciso levar em consideração o "contexto do contexto" ou, como sintetizaram Casotti e Suarez (2016): "as forças ideológicas e conjunturais que produzem subjetividades e moldam formas específicas de agência" (p. 354).

$\mathrm{Na}$ contracorrente dessa discussão estão Cova, Maclaren and Bradshaw (2013) que exigem um pensamento mais radical, "de raiz" e de resistência à "cooptação" do marketing nos estudos da CCT. Bode and Østergaard (2013), por sua vez, propõem que haja um equilíbrio entre "vozes radicais e pragmáticas" (p. 175) no intuito de favorecer um crescimento sustentável e dinâmico da CCT.

Nosso intuito ao expor as discussões travadas entre os artífices da CCT foi retratar que as preocupações da comunidade CCTiana não estão circunscritas à produção de artigos acadêmicos. Vão além, pois demonstram a constante (e saudável) preocupação dos pesquisadores acerca dos limites e avanços de atuação pela própria Consumer Culture Theory, os quais, consequentemente, impactam diretamente nos rumos e contribuições da pesquisa sobre o consumo.

Retomando a lista de pesquisadores com contribuições teóricas e empíricas para a CCT, faz-se necessário incluir os trabalhos de Schouten and McAlexander (1995), que introduziram o conceito de subcultura de consumo como uma categoria analítica por meio da qual é possível compreender como os consumidores vivem e expressam suas identidades. No artigo em questão, os autores analisaram o comportamento dos proprietários de motocicletas da marca Harley Davidson, realizando uma pesquisa etnográfica de cerca de três anos. Kozinets (2014), por sua vez, introduziu o conceito de "Netnografia" ao campo de pesquisa de consumidor e revolucionou as pesquisas sobre comportamento de consumo em ambientes online.

Um autor que realizou, mesmo que indiretamente, contribuições fundamentais para a pesquisa de consumo e a fundamentação do que hoje é a CCT foi Levy que, em 1959, publicou o emblemático "Symbols for Sale", no qual, à época, chamava a atenção de empresários e gestores de marketing para as subjetividades e significados simbólicos envolvidos no processo de decisão de compra dos consumidores e atrelados às suas percepções sobre marcas de seus produtos. E, anos depois contribui para o desenvolvimento das pesquisas qualitativas ao sugerir uma técnica que leva em consideração a interpretação do simbolismo característico das verbalizações dos consumidores no artigo "Interpreting Consumer Mythology: A Structural Approach to Consumer Behavior". Em 2006, escreveu um capítulo sobre a história da pesquisa qualitativa em marketing para uma publicação editada por Russell Belk, "Handbook of Qualitative Research Methods in Marketing".

Nesta linha, não poderíamos deixar de fora Grant McCraken, estudioso precursor da cultura de consumo que cunhou o conceito de "movimento do significado cultural" (1986) e que, em 2003, publicou um livro no qual aprofunda seus estudos sobre o tema e que é referência nas aulas e debates sobre CCT. 
Por fim, e não menos importante, mister apontar quem são os pesquisadores e produções acadêmicas que desenharam os contornos da CCT no nosso País. Para começar temos, além de Casotti, já citada neste artigo em parcerias com Belk (2014) e Suarez (2016), a professora Lívia Barbosa que organizou, juntamente com Campbell, um conjunto de papers escritos por sociólogos e antropólogos brasileiros e estrangeiros intitulado "Cultura, Consumo e Identidade" (Barbosa \& Campbell, 2006). A autora também publicou estudos sobre o jeitinho brasileiro (2002) e a Sociedade de Consumo (2004), dentre outros.

Nos valendo, ainda, do texto de Belk and Casotti (2014) em que afirmam que, a partir da segunda metade da década de 2000, houve, juntamente com uma maior abertura para a realização de metodologias qualitativas nas pesquisas de marketing, uma expansão da produção acadêmica brasileira sobre a diversidade cultural do País. Emergem no cenário acadêmico nacional estudos empíricos e bibliométricos sobre consumo e identidade (Barboza \& Ayrosa, 2013; Barros et al., 2010), consumo de baixa renda (Pinto, 2009), homossexuais (Pereira \& Ayrosa, 2012) e consumo de pessoas com deficiência (Correa, Pinto \& Batinga, 2016), para citarmos alguns destes.

Em 2018, Pinto e Batinga (2018) organizam um livro composto por uma coletânea de trabalhos com a participação de 23 autores, incluindo professores e pesquisadores, doutorandos e mestres de diferentes estados brasileiros. Nessa iniciativa, apresenta-se o estado atual das pesquisas em CCT no Brasil, descrevem-se alguns estudos tendo a corrente como base teórica e apontam-se novas perspectivas para os estudos desse campo no Brasil.

Esses são alguns dos pesquisadores artífices da comunidade da CCT no Brasil que, por meio de trabalhos empíricos em conjunto com seus orientandos buscam compreender, dentro do contexto brasileiro, as relações entre cultura e consumo nas suas mais diversas manifestações. Infelizmente, devido às limitações impostas, deixamos de contemplar vários estudos que demonstram o crescimento da CCT no Brasil.

A seguir, a última parada de nossa viagem.

\section{CONSIDERAÇÕES FINAIS}

Este artigo é fruto de pesquisas e de longas discussões de um grupo de alunos de pósgraduação em Administração, imbuído do interesse genuíno de conhecer e também contribuir para o fortalecimento e avanços da CCT no Brasil. O grupo se debruçou sobre as leituras expostas neste artigo (dentre diversas outras), a fim de "consumir" o máximo de informação possível e tentar transpô-la na forma de aprendizado sistematizado em futuras pesquisas, as quais possam refletir não apenas a teoria, mas principalmente "o jeito de ser" de um pesquisador da CCT, qual seja: aquele que vai a campo sem hora de sair, que tira impressões, mas não se contenta com elas, que se (re)questiona, emociona e que, principalmente, acredita naquilo que está estudando. Apesar disso, buscando não "romantizar" o que constitui o trabalho de um pesquisador da CCT, não é escusado afirmar que uma pesquisa atrelada ao campo da cultura e consumo apresenta também percalços, dificuldades e angústias. A maioria delas advém dos desafios do estar no campo sem um "modelo" pré-estabelecido e sem uma noção clara de quando as peças do quebra-cabeça oferecidas pela complexidade da realidade passarão a fazer sentido.

Apesar disso, cientes de que o consumo é um campo vasto, muitas vezes ambíguo, o mesmo nos oferece infinitas possibilidades de questionamentos, hipóteses, discussões e quem sabe até conclusões - o que pode ser entusiástico e também assustador: como "sobreviver" às "angústias" da pesquisa de consumo sem um forte conjunto de teorias que nos referencie epistemologicamente e nos sustente metodologicamente?

Por isso, entendemos que a melhor contribuição que podemos dar à CCT é não pararmos de estudar e refletir sobre ela. Mais do que refletir, precisamos senti-la e, sempre 
que possível, transmitir nosso entusiasmo a todos os interessados, quer sejam docentes ou discentes, que desejarem se aventurar a viajar pelos trilhos da pesquisa de consumo e a embarcarem nesta incrível jornada que é a Consumer Culture Theory. Jornada essa na qual seus tripulantes precisam estar atentos às tendências internacionais do campo por meio do acesso aos principais journals estrangeiros e livros que vêm sendo publicados sobre a temática (entre eles Sherry Jr. \& Fischer (2017) e Arnould \& Thompson (2018)). Outrossim, esses mesmos tripulantes ainda não devem deixar de estar sensíveis e preocupados com o alinhamento que deve ser dado às pesquisas ao nosso contexto, marcado por características muito peculiares e que podem servir de base para outros pesquisadores.

Esta é a mensagem que desejávamos passar ao compartilharmos nossa experiência em torno das discussões que fizemos no último ano. Ao apontarmos alguns dos trabalhos mais significativos da área, esperamos tê-los feito perceber que, afinal, a CCT está sempre em movimento e, portanto, não tem uma parada final. Na verdade, está apenas começando! Que a essa jornada possam se juntar outros interessados em viajar "por mares, nunca dantes navegados".

\section{REFERÊNCIAS}

Arnould, E., \& Thompson, C. (2005). Consumer culture theory (CCT): Twenty years of research. Journal of Consumer Research, 31(4), 868-882.

Arnould, E., \& Thompson, C. (2007). Consumer culture theory (and we really mean theoretics. In Consumer Culture Theory (pp. 3-22). Emerald Group Publishing Limited.

Arnould, E., \& Thompson, C. (2018). Consumer Culture Theory. Los Angeles: Sage Publications.

Askegaard, S., \& Linnet, J. T. (2011). Towards an epistemology of consumer culture theory: Phenomenology and the context of context. Marketing Theory, 11(4), 381-404.

Barbosa, L. (2004). Sociedade de consumo. Zahar.

Barbosa, L. \& Campbell, C. (2006). (Orgs.). Cultura, consumo e identidade. FGV Editora.

Barboza, R. A., \& Ayrosa, E. A. T. (2013). Um estudo empírico sobre a construção da identidade social do consumidor de Toy Art. Revista de Ciências da Administração, 1, 11-21.

Barros, D. F., Sauerbronn, J. F. R., Costa, A. M., \& Darbilly, L. V. (2010). Download, pirataria e resistência: uma investigação sobre o consumidor de música digital. Comunicação, Mídia e Consumo, 7, 125-151.

Belk, R. (1984). Manifesto for a consumer behavior of consumer behavior. Scientific Method in Marketing, 163-67.

Belk, R. (1987a). The role of the Odyssey in consumer behavior and in consumer research. NA-Advances in Consumer Research Volume 14.

Belk, R. (1987b), "A Child's Christmas in America: Santa Claus as Deity, Consumption as Religion,” Journal of American Culture, 10 (1), Spring, 87-100. 
Belk, R. (1988). Possessions and the extended self. Journal of consumer research, 15(2), 139168.

Belk, R., Wallendorf, M., \& Sherry Jr, J. F. (1989). The sacred and the profane in consumer behavior: Theodicy on the odyssey. Journal of consumer research, 16(1), 1-38.

Belk, R. (1991). The history and development of the consumer behavior odyssey. ACR Special Volumes.

Belk, R. (1992), "Attachment to Possessions," in Irwin Altman and Setha Low, ed., Human Behavior and Environment: Advances in Theory and Research, Vol. 12, Place Attachment, New York: Plenum Press, 37-62.

Belk, R, \& Tumbat, G. (2005). The cult of Macintosh. Consumption markets \& culture, 8(3), 205-217.

Belk, R. (2009). Sharing. Journal of consumer research, 36(5), 715-734.

Belk, R. W. (2013). Extended self in a digital world. Journal of Consumer Research, 40(3), 477-500.

Belk, R. (2014). The Labors of the Odysseans and the Legacy of the Odyssey. Journal of Historical Research in Marketing, 6(3), 379-404.

Belk, R., \& Casotti, L. M. (2014). Ethnographic Research in Marketing: Past, Present, and Possible Futures. Revista Brasileira de Marketing, 13(6).

Belk, R. (2017). Russ Belk, autobiographical reflections. Journal of Historical Research in Marketing, 9(2).

Bode, M., \& Østergaard, P. (2013). 'The wild and wacky worlds of consumer oddballs' analyzing the manifestary context of consumer culture theory. Marketing Theory, 13(2), 175192.

Burrell, G. \& Morgan, G. (1979). Sociological paradigms and organizational analysis. Aldershot: Ashgate.

Campbell, C. (2004). O Consumidor Artesão: Cultura, artesania e consumo em uma sociedade pós-moderna. Antropolítica, 17, 45-67.

Casotti, L. M., \& Suarez, M. C. (2016). Dez anos de consumer culture theory: delimitações e aberturas. Revista de Administração de Empresas, 56(3), 353-359.

Correa, R. S., Pinto, M. R., \& Batinga, G. L. (2016). A beleza na escuridão: um “olhar” sobre a experiência de consumo por mulheres deficientes visuais em serviços de beleza e estética. Revista Ciências Administrativas, 22(2), 371-395.

Cova, B., Maclaran, P., \& Bradshaw, A. (2013). Rethinking consumer culture theory from the postmodern to the communist horizon. Marketing Theory, 13(2), 213-225. 
Duarte, A. (2010). A Antropologia e o Estudo do Consumo: revisão crítica das suas relações e possibilidades. Etnográfica, 14(2), 361-393.

Gaião, B. F. S., Souza, I. L. \& Leão, A. L. S. (2012). Consumer Culture Theory (CCT) Já é uma escola de pensamento em Marketing? Revista de Administração de Empresas, 52(3), $330-344$

Geertz, C. (1973). The interpretation of cultures (Vol. 5019). Basic Books.

Graeber, D., Cluley, R., Harvie, D., Doukas, D., Girke, F., Hornborg, A., \& Graeber, D. (2011). Consumption. Current Anthropology, 52(4), 000-000.

Hall, S. (2011). A identidade cultural na pós-modernidade. $11^{\mathrm{a}}$. Ed. Rio de Janeiro: DP\&A Editora.

Hirschman, E. C. (1986). Humanistic inquiry in marketing research: philosophy, method, and criteria. Journal of marketing Research, 237-249.

Holbrook, M. B. (1987). What is consumer research? Journal of Consumer Research, 14(1), 128-132.

Kassarjian, H. H. (1987). How we spent our summer vacation: A preliminary report on the 1986 Consumer Behavior Odyssey. NA-Advances in Consumer Research Volume 14.

Kassarjian, H. H., \& Goodstein, R. C. (2010). The emergence of consumer research. In: Maclaran, P., Saren, M., Stern, B., \& Tadajewski, M. (eds) The Sage Handbook of Marketing Theory. London: Sage Publications.

Kozinets, R. V. (2010). Netnography: Doing ethnographic research online. Sage Publications.

Kozinets, R. V. (2014). Netnografia: realizando pesquisa etnográfica online. (B. Daniel, Trad.). Porto Alegre: Editora Penso. (Obra original publicada em 2010).

Levy, S. J. (1999). Symbols for sale. Brands, Consumers, Symbols and Research: Sidney J Levy on Marketing, 203-212.

Levy, S. J. (1981). Interpreting consumer mythology: a structural approach to consumer behavior. The Journal of Marketing, 49-61.

Levy, S. J. (2006). History of qualitative research methods in marketing. Handbook of qualitative research methods in Marketing, 3-16.

MacInnis, D.; Folkes, V. S. (2010). The Disciplinary Status of Consumer Behavior: A Sociology of Science Perspective on Key Controversies. Journal of Consumer Research, 36(6), 899-914.

McCracken, G. (1986). Culture and consumption: A theoretical account of the structure and movement of the cultural meaning of consumer goods. Journal of consumer research, 13(1), 71-84. 
Pereira, S. J. N., \& Ayrosa, E. A. T. (2012a). Between two worlds: on ethnographic study of gay consumer culture in Rio de Janeiro. BAR, 9, 211228.

Pinto, M. R. (2009). Os pobres e o consumo, uma teoria substantiva da experiência de consumo de eletrônicos (Tese de doutorado). Universidade Federal de Minas Gerais, Belo Horizonte, MG, Brasil.

Pinto, M. R., \& Batinga, G. L. (org.) (2018). Cultura e Consumo no Brasil: estado atual e novas perspectivas. Belo Horizonte: Editora PUC Minas.

Pinto, M. R., \& Santos, L. L. S. (2008). Em Busca de uma Trilha Interpretativista para a Pesquisa do Consumidor: Uma Proposta Baseada na Fenomenologia, na Etnografia e na Grounded Theory. RAE-Eletrônica, 7(2), 1-28.

Retondar, A. M. (2007). A (re) construção do indivíduo: a sociedade de consumo como "contexto social" de produção de subjetividades. Sociedade e Estado, 23(1).

Sandikci, O., \& Ger, G. Veiling in Style: How Does a Stigmatized Practice Become Fashionable?, Journal of Consumer Research, 37(1), 2010, 15-36.

Sherry Jr, J. F. (1983). Gift giving in anthropological perspective. Journal of consumer research, 10(2), 157-168.

Sherry Jr, J. F. (1987). Keeping the monkeys away from the typewriters: an anthropologist's view of the Consumer Behavior Odyssey. Advances in consumer research, 14(1).

Sherry Jr., F., \& Fischer, E. (eds). (2017) Contemporary Consumer Culture Theory. New York: Routledge.

Schouten, J. W., \& McAlexander, J. H. (1995). Subcultures of consumption: An ethnography of the new bikers. Journal of consumer research, 22(1), 43-61.

Thompson, C. J. (1991). May the circle be unbroken: a hermeneutic consideration of how interpretive approaches to consumer research are understood by consumer researchers. NAAdvances in Consumer Research Volume 18.

Thompson, C. J., Arnould, E., \& Giesler, M. (2013). Discursivity, difference, and disruption: Genealogical reflections on the consumer culture theory heteroglossia. Marketing Theory, 13(2), 149-174.

Wallendorf, M. (1987). On the road again: the nature of qualitative research on the consumer behavior odyssey. NA-Advances in Consumer Research Volume 14.

Wilk, R. (2004). Morals and metaphors: the meaning of consumption. Elusive consumption, 11-26. 